\title{
Magnitude and frequency: challenges for the assessment of vulnerability to geomorphic hazards
}

\author{
S. Fuchs ${ }^{1}$, M. Keiler ${ }^{2} \&$ T.-C. Tsao ${ }^{3}$ \\ ${ }^{1}$ Institute of Mountain Risk Engineering, \\ University of Natural Resources and Life Sciences, Vienna, Austria \\ ${ }^{2}$ Institute of Geography, University of Bern, Switzerland \\ ${ }^{3}$ Sinotech Engineering Consultants, INC., Taipei, Taiwan, ROC
}

\begin{abstract}
In natural hazard research, risk is defined as a function of (1) the probability of occurrence of a hazardous process, and (2) the assessment of the related extent of damage, defined by the value of elements at risk exposed and their physical vulnerability. Until now, various works have been undertaken to determine vulnerability values for objects exposed to geomorphic hazards such as mountain torrents. Yet, many studies only provide rough estimates for vulnerability values based on proxies for process intensities. However, the deduced vulnerability functions proposed in the literature show a wide range, in particular with respect to medium and high process magnitudes. In our study, we compare vulnerability functions for torrent processes derived from studies in test sites located in the Austrian Alps and in Taiwan. Based on this comparison we expose needs for future research in order to enhance mountain hazard risk management with a particular focus on the question of vulnerability on a catchment scale.
\end{abstract}

Keywords: exposure, vulnerability, torrents, risk management, Taiwan, Austria.

\section{Introduction}

Major losses in mountain areas are associated with torrent events [1,2]. The term torrent refers to steep rivers within mountain environments. Torrents are defined as constantly or temporarily flowing watercourses with strongly changing perennial or intermittent discharge and flow conditions [3] within small catchment areas [4]. At the outlet of these watersheds, torrent fans are developed 
which are used for settlement purposes since the beginning of the historical colonisation and commodification of the landscape. Therefore, torrent events are a main challenge for society in many countries, in particular due to the spatial overlap of these settlements with the potential deposition area in periods of extraordinary discharge.

To respond to these challenges the concept of risk has been introduced in natural hazard management, and experiences from past years suggested that elements at risk and vulnerability should be increasingly considered within the framework of hazard management in order to reduce losses (e.g. [5]). However, the review of the concept of risk for mountain areas resulted in gaps concerning appropriate tools for the assessment of vulnerability of elements at risk and of communities exposed [6]. To overcome these shortcomings, studies on vulnerability have been undertaken aiming at (1) the methodological development of loss functions with respect to buildings located in the run-out areas of torrent processes [7-9]; and (2) the conceptualisation of an overarching vulnerability model including structural, economic, social and institutional vulnerability [10]. Apart from Tsao et al. [8], whose work was related to the mountain areas of Taiwan, these studies were all focusing on the quantification of vulnerability in the European Alps. These studies were rooted in an ex-post assessment of the event magnitude or intensity, the level of loss and the reinstatement value of the buildings at risk in order to obtain a damage ratio. By combining these three factors, vulnerability curves were deduced for both, debris flows [7, 8] and fluvial sediment transport [9].

When comparing the results of those studies undertaken in the European Alps with the Taiwanese data, considerable differences and methodological issues arise. These aspects will be discussed in the following sections in order to provide an outlook of the challenges that come up when a method developed within the specific setting in one mountain region is transferred to another region of the world with a slightly different setting. The aim is to highlight possible pitfalls and shortcomings in order to contribute to the ongoing discussion on vulnerability to torrent events in mountain areas; therefore, (1) possible aspects of physical vulnerability will be discussed but also (2) the wider implications with respect to social vulnerability.

\section{Quantification of vulnerability}

The assessment of vulnerability requires an ability to both identify and understand the susceptibility of elements at risk and - in a broader sense - of the society to these hazards. Studies related to vulnerability of human and natural systems to mountain hazards, and of the ability of these systems to adapt to changes in the functional chain of hazards, are a relatively recent field of research that brings together experts from a wide range of disciplines. Researchers from these disciplines bring their own conceptual models to study vulnerability and adaptation, models which often address similar problems and processes using different languages. However, apart from the overall discussion on linguistic placements and semantic dimensions of the term $[11,12]$, 
vulnerability in the context of mountain natural hazards is usually defined as the physical impact of hazardous events on elements at risk. Accordingly, if quantitatively assessed, vulnerability is defined as the expected degree of loss for an element at risk due to the impact of a defined hazardous event within a defined period of time and a defined location. These events are themselves conditioned by a certain intensity, frequency and duration, all of which affect vulnerability. From this technical point of view, as a general rule, vulnerability assessment is based on the evaluation of parameters and factors such as building categories or types, construction materials and techniques, state of maintenance, presence of protection structures, and presence of warning systems [13]. Nevertheless, many of these factors are usually not assessed, above all due to limitations in the assessment method and due to practical limitations of feasibility. For this reason, vulnerability values are used to describe the susceptibility of elements at risk to damage, which is conceptualised by a damage ratio between loss and the value of affected elements at risk, facing different process types with different spatial and temporal distributions of process intensities (e.g., flow depths, accumulation levels, and pressures).

The damage ratio is quantified using an economic approach by establishing a ratio between the loss and the reconstruction value of every individual element at risk exposed. In a second set of calculations, this ratio obtained for every individual element at risk is linked to the respective process intensities which are regularly documented ex-post by the respective authorities or their subcontractors. The relation between damage ratio and process intensity is further defined as vulnerability. For such assessment information on the elements at risk exposed on the individual torrent fans is necessary, as well as data on the process intensities of the particular hazardous events. As a result, scatter plots can be developed linking process intensities to object vulnerability values [7]. These data can be analysed using regression approaches in order to develop vulnerability functions, which serve as a proxy for the structural resistance of buildings with respect to fluvial sediment transport processes or debris flows on the studied torrent fans.

\section{Test sites in Austria}

Taking fluvial sediment transport as an example, Totschnig et al. [9] presented a vulnerability function which was deduced from three well-documented events in the Austrian Alps. In total, 116 buildings were damaged in the three test sites, 67 of which were residential buildings and were included in their study. The total damage of the houses considered amounted to approximately $€ 5.5$ million while the individual loss was between $€ 438$ and $€ 828,240$. Because of different building sizes, the reconstruction values showed a wide range from about $€ 221,000$ to $€ 1.34$ million. These variations lead to individual vulnerabilities ranging from 0.001 to 1.0 , whereas the mean vulnerability per exposed building was equal to 0.168 . In Tab. 1, damage and property values, the range of vulnerability, and the mean vulnerability per exposed residential building for the individual test sites is shown. 
Table 1: Number of buildings, reported loss, property value, range of vulnerability, and mean vulnerability for each test site in the Austrian Alps.

\begin{tabular}{|l|r|r|r|r|r|}
\hline Test site & \multicolumn{1}{|l|}{$\begin{array}{l}\text { Buildings } \\
{[\mathrm{N}]}\end{array}$} & $\begin{array}{l}\text { Reported } \\
\text { loss }[€]\end{array}$ & $\begin{array}{l}\text { Property } \\
\text { value }[€]\end{array}$ & $\begin{array}{l}\text { Range in } \\
\text { vulnerability }\end{array}$ & $\begin{array}{l}\text { Mean } \\
\text { vulnerability }\end{array}$ \\
\hline Pfunds & 28 & $4,851,800$ & $13,483,267$ & $0.013-1.000$ & 0.369 \\
\hline Schnann & 10 & 403,700 & $6,444,471$ & $0.005-0.131$ & 0.045 \\
\hline St. Stefan & 29 & 260,509 & $17,629,091$ & $0.001-0.045$ & 0.015 \\
\hline
\end{tabular}

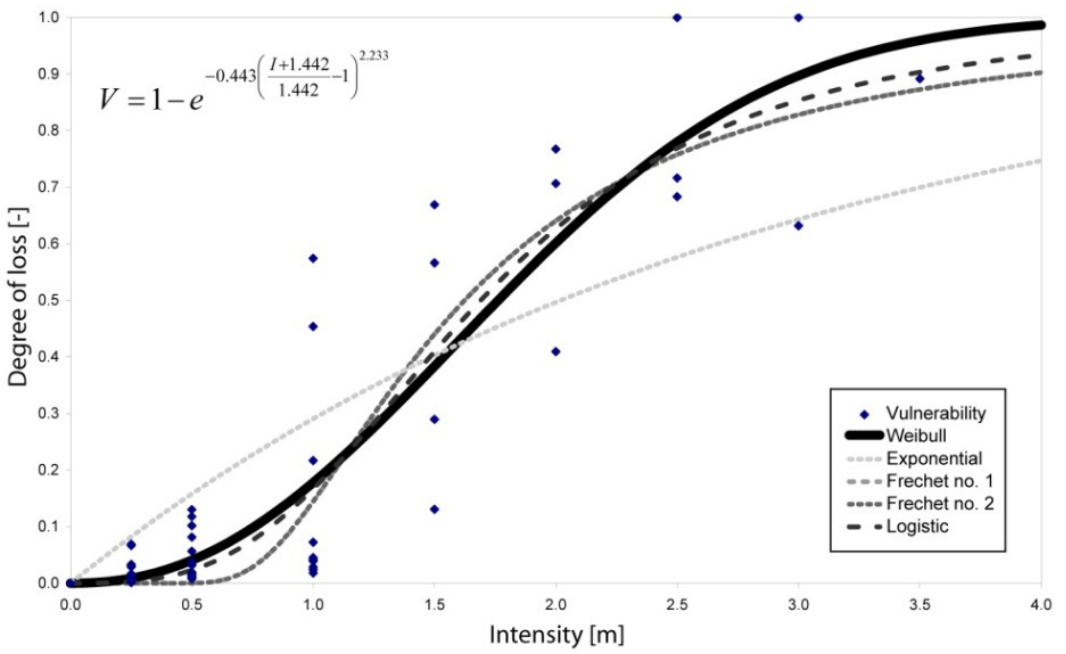

Figure 1: Different vulnerability functions for residential buildings based on deposition height as a proxy for the process intensity. Vulnerability values originating from the study sites are indicated by dots. The best-fitting function to describe the range in the analysed data (Weibull) is highlighted in bold, and is provided in terms of the mathematical notation $(\mathrm{V}=$ degree of loss, $\mathrm{I}=$ intensity, modified from [9]).

In Fig. 1 the resulting vulnerability curve is shown, based on absolute deposition heights as a proxy for process intensities in the affected area. The process intensity is plotted on the abscissa and the damage ratio is plotted on the ordinate. In general, vulnerability increases with increasing intensity. For low process intensities $(\mathrm{I}<1 \mathrm{~m})$ all distributions show a slow increase in vulnerability. For medium process intensities $(1 \mathrm{~m} \leq \mathrm{I} \leq 2.5 \mathrm{~m})$ the highest rate of increase in vulnerability is observed, following an almost linear shape. For high process intensities ( $\mathrm{I}>2.5 \mathrm{~m}$ ) the observed rate of increase in vulnerability again decreases and the curves converge towards 1. Due to these specific shapes, the effect of an increase in process intensity is different in all three sections of these curves; an increase in process intensity of $0.5 \mathrm{~m}$ causes as such more 
additional damage at medium process intensities if compared to low and high intensities. For the process intensity of $1.0 \mathrm{~m}$ to $1.5 \mathrm{~m}$, the statistical spread of the vulnerability values is considerable, which can be attributed to a possible intrusion of material through building openings [7]. The best-fitting function to describe the range in the analysed data (highest value of utility) is a modified Weibull distribution [9], which is highlighted in bold in Fig. 1.

Physical susceptibility of elements at risk and thus vulnerability is strongly dependent on the construction material used. The developed vulnerability function is applicable to buildings which are constructed by using brick masonry and concrete, a typical design in post-1950s building craft in Alpine countries. Consequently, the adjusted function may be applicable to this mixed construction type. However, a wider application of the presented approach to additional building types such as reinforced concrete was repeatedly claimed as outstanding [10], and will be presented in the following section.

\section{Test sites in Taiwan}

Data from six counties were used in order to apply the method in mountain areas of Taiwan, almost all of them from torrent events that occurred as a result from one typhoon event. On 7 August 2009, typhoon Morakot hit Taiwan, resulting in $>600$ dead and $>70$ missing persons, a temporary evacuation of almost 25,000 residents, and $>€ 3.6$ billion economic loss [13]. For 39 buildings, the process intensity and the loss were recorded after the event with sufficient accuracy. These buildings with a damage ratio between 0.05 and 1.0 were included in our analysis (Tab. 2).

Table 2: Construction material, number of buildings considered, range in process intensity and vulnerability, and mean vulnerability for each construction type in the test sites in Taiwan.

\begin{tabular}{|l|r|r|r|r|}
\hline $\begin{array}{l}\text { Construction } \\
\text { material }\end{array}$ & $\begin{array}{l}\text { Buildings } \\
{[\mathrm{N}]}\end{array}$ & $\begin{array}{l}\text { Range in process } \\
\text { intensity [m] }\end{array}$ & $\begin{array}{l}\text { Range in } \\
\text { vulnerability }\end{array}$ & $\begin{array}{l}\text { Mean } \\
\text { vulnerability }\end{array}$ \\
\hline Wood & 3 & $1.0-3.0$ & - & 1.00 \\
\hline Sheet metal & 4 & $1.0-2.0$ & $0.05-1.00$ & 0.76 \\
\hline Brick & 16 & $1.0-3.5$ & $0.05-1.00$ & 0.71 \\
\hline $\begin{array}{l}\text { Reinforced } \\
\text { brick }\end{array}$ & 10 & $1.5-4.0$ & $0.10-1.00$ & 0.63 \\
\hline $\begin{array}{l}\text { Reinforced } \\
\text { concrete }\end{array}$ & 6 & $1.6-5.0$ & $0.20-1.00$ & 0.73 \\
\hline
\end{tabular}

The best fitting function was again a Weibull function, however, with a very low coefficient of determination $\left(\mathrm{R}^{2}=0.172\right)$. This is due to the wide range in process intensities observed, which are clearly above the intensities usually observed in European mountain regions. As a result, the mean vulnerability is also considerably higher than the mean values reported in Tab. 1 for the Austrian test sites. To give an example, four out of six buildings composed of reinforced concrete were affected by process intensities between $3.0 \mathrm{~m}$ and $5.0 \mathrm{~m}$ which 
obviously resulted in a high degree of loss and therefore also in a comparatively high mean vulnerability. Moreover, the study involved buildings with different construction material used, and therefore the resistance towards the impact of torrent processes is considerably different.

During the field work, 13 buildings were assessed with a process intensity between 1.0 and $2.0 \mathrm{~m}$ and a damage ratio of $100 \%$, which seems to be high compared with data presented for the European Alps (due to the overlap only six data points are visible in Fig. 2). These buildings were composed of bricks (7 buildings), wood ( 2 buildings), sheet-metal (3 buildings) and reinforced concrete ( 1 building). Only when these 13 buildings were excluded from the analysis, the Weibull function followed a similar shape to the one of the Austrian case study (Fig. 2), and the coefficient of determination became reasonable $\left(\mathrm{R}^{2}=0.739\right)$. Apparently, this is not the aim of a statistical treatment of data, since the exclusion of nearly one third of data from the population leads to considerable biases, and restricts the overall explanatory power.

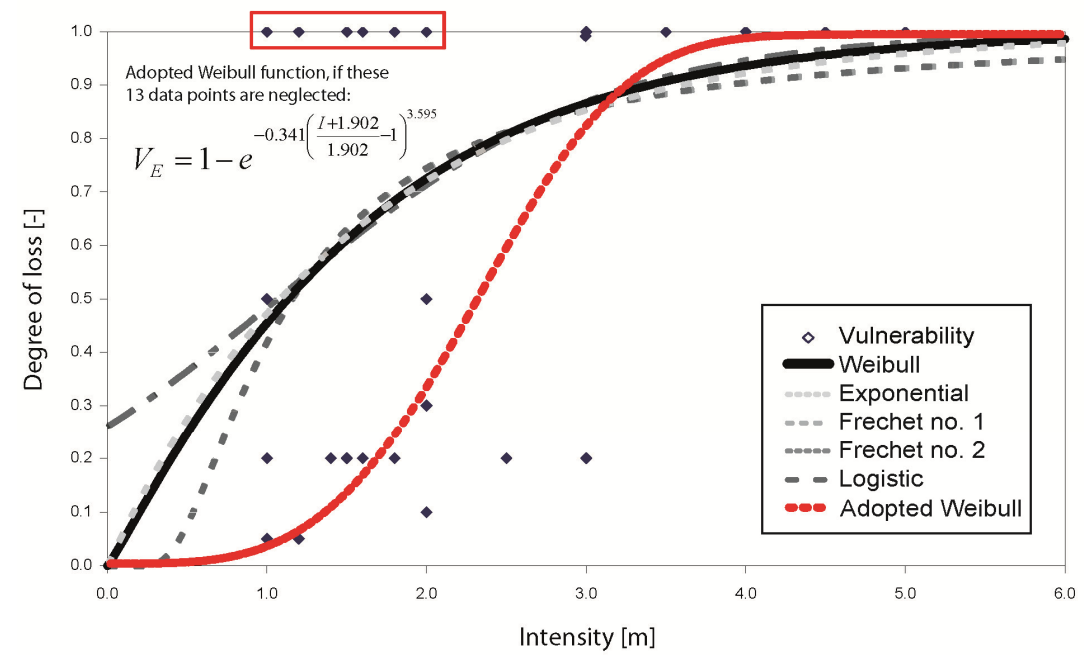

Figure 2: Different vulnerability functions for buildings based on deposition height as a proxy for the process intensity. Vulnerability values originating from the study sites are indicated by dots. The bestfitting function to describe the range in the analysed data (highest value of utility; Weibull) is highlighted in bold. Since between 1.0 and $2.0 \mathrm{~m}$ process intensity, 13 buildings were assessed with a damage ratio of 1.0, the best fitting approach did not result in reasonable outcomes. When these data points were neglected in the statistical treatment, an adopted Weibull function resulted that is provided here in terms of the mathematical notation $(\mathrm{V}=$ degree of loss, I = intensity). 


\section{Limitations of transfer}

The application of a method developed in the context of the European Alps when compared with another mountain environment clearly has some limitations:

(1) The first shortcoming is that in environments affected by tropical cyclones much higher rainfall intensities are observed than in regions characterised by a warm-temperate maritime and continental climate sensu Lauer and Frankenberg [15]. As a result, the triggered torrent magnitudes and intensities are much higher.

(2) Secondly, unlimited sediment supply - amplified by a multi-hazard situation such as translational landsliding of the slopes in the upper part of the torrent catchments [16], which leads to a temporal channel blocking and a subsequent erosion with a high flood hydrograph [17] - may result in process patterns other than those observed in the European Alps so far.

Putting these two aspects in a broader context, the application of the concept of frequency and magnitude to different mountain environments may be the explanation for these different system behaviours in Austria and Taiwan: Each process has internal threshold values or external trigger values at which the process becomes effective and is initiated, and sediment transport and landform change is mobilised [18]. Since the work of Melton [19] there have been many attempts to predict the frequency or magnitude of torrent processes based on basin variables [20] in combination with geomorphic indicators [21]. Traditional approaches to determining frequency and magnitude have centred on fluvial processes [22] and have dealt with frequency in terms of discrete hydrological events and magnitude by measures of volume or mass of water and sediment associated with those events. They assume a direct relationship between the hydrological processes and the geomorphic response, such as the capacity of the water body to entrain and transport a certain amount of sediment in dependence of the exerted shear stress (combination of flow velocity and flow depth) and the grain size [23]. Therefore, these approaches have been empirically applied to a wide spectrum of geomorphic processes in recent decades [see e.g., 24]. With respect to torrent processes, such a frequency-magnitude approach (1) provides the rationale for extrapolating short-term measurements of episodic processes over longer periods, and (2) allows at a first glance the statistical identification of the most relevant work force operating within a system, thereby providing a key variable for predicting other system qualities [25] such as vulnerability. Nevertheless, multi-hazard patterns - understood in terms of a hazard chain such as landsliding and subsequent channel blocking within a catchment - are not a priori identifiable with such an approach.

Focusing on the elements at risk exposed the damage patterns observed vary considerably. Even if building materials used and construction techniques employed differ between the two case studies, buildings in Taiwan and in Austria are regularly filled with debris material, which penetrated through building openings and damaged outer walls (Fig. 3). While in Taiwan these buildings are either reinforced brick based on a concrete frame or reinforced 
concrete (16 out of 39 buildings studied), often due to the earthquake-resistance building codes, the typical alpine building style is dominated by brick masonry and concrete base-plates. As a result, given the same impact pressure the buildings in Austria would collapse while the buildings in Taiwan would still resist even if an economic total loss is evident, as shown in Fig. 3, upper right. In Taiwan buildings are regularly heavily damaged (damage ratio $>50 \%, 25$ out of 39 buildings), while in Austria only few buildings are a total loss [9]. These differences are again a result of different impact towards exposed elements at risk, resulting from different process characteristics.
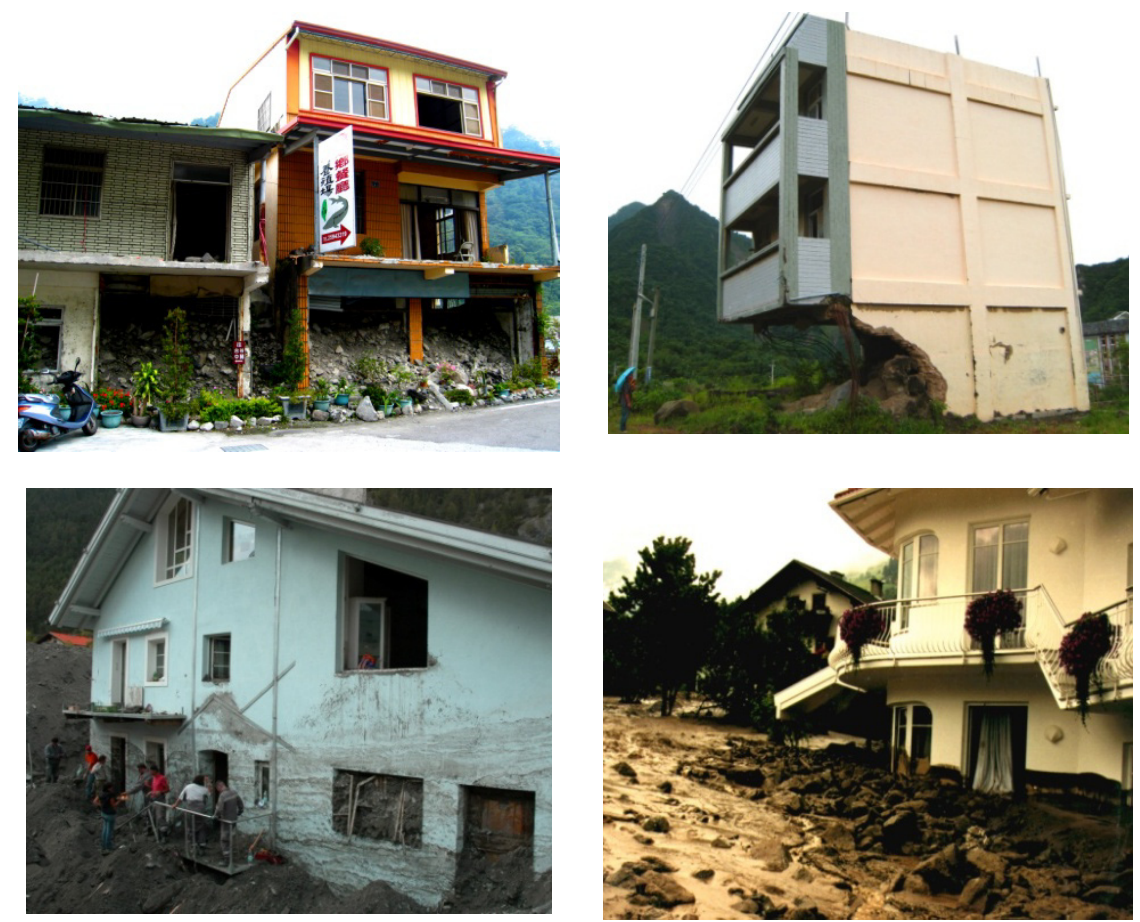

Figure 3: Typical damage patterns for buildings affected by torrent processes in Taiwan (top) and Austria (bottom). Upper left: Songhe community, Taiwan, August 2004, upper right: Min-Zu community, Taiwan, August 2009, lower left: Pfunds community, Austria, August 2005, lower right: Wartschensiedlung village, August 1997. Credits: upper left and right: S. Fuchs, lower left: GBL 6.2, lower right: anonymous.

With respect to the recorded losses, some issues arise for transfer of the method. In the Austrian case studies, loss data was collected using information derived from the individual administrative bodies on the Federal State level. Professional damage appraisers of these administrative bodies estimated the loss 
of any individual element at risk in monetary terms on an object level. Losses that can be attributed to the building envelope only were identified and prepared for the subsequent analysis. These monetary loss assessments were applied within this study for the calculation of the damage ratio of every individual element at risk, defined by the ratio between loss and reconstruction value. The case studies in Taiwan were assessed similarly, however, if the claimant received compensation in terms of an alternative building supplied by the governmental administration, by public social aid or relief organisations, the loss ratio of the damaged building had to be assessed with 1.0 since a further economic use of the (partly) damaged structure is not allowed. This regulation necessarily leads to some biases during the economic assessment of the loss ratio, such as for the building shown in Fig 3, upper left: Even if the accumulated debris could be removed from the interior, and even if serious structural damage was not reported, the building had to be abandoned and therefore the loss ratio equals the construction costs of the building. In contrast, if the claimant is not supplied with a new building in an alternative location, the governmental compensation in Taiwan is a lump sum independent from the damage level, while losses in Austria (if they are compensated, compared with the discussion in [26]) are in relation to the actual amount of damage.

\section{Discussion}

Two particular challenges were identified during the comparison of case studies carried out in Austria and in Taiwan. Firstly, event documentation is a requirement to precisely identify process patterns and to provide an accurate input into hazard modelling. Secondly, a legally prescribed land-use planning and associated building regulation are inevitably necessary if future losses due to torrent events should be reduced. Legislation related to natural hazards is diverse in both countries studied. Due to the federal structure of the Republic of Austria, several articles at federal level are supplemented by various regulations on the level of the Federal States and even below at community level, in particular with respect to land use planning [26]. In Taiwan, the Disaster Prevention and Protection Act was issued in the year 2000. However, this act is less focused on regional development and land use planning than the Austrian regulations are. It is rather centred on disaster response and recovery responsibilities of governmental agencies. A regulation or ordinance related with land development and land use zoning on a national scale has been under development for almost two decades. On a regional scale, the Geology Act recently put into force regulates some development restrictions with respect to natural hazards, however, the enforcement with respect to hazard mapping and zoning will still take some years for a comprehensive implementation. Land use planning activities such as hazard maps are based on the concept of recurrence intervals of hazard processes. Since the hazard potential and thus the delimitation of hazard zones is subject to temporal changes, the resulting coping strategies in order to minimise risk have to be variable. From the point of view of spatial planning dealing with such changes is of particular difficulty since the required stability of 
the law restricts short-term modifications in land use planning regulations to a minimum. In particular building bans and re-zoning of already permitted land development activities remain an unsolved task since once enacted and approved by the regulatory authority additional prescriptions or prohibitions could hardly be accomplished. Hence, the overlap between hazard areas and areas used for settlement purpose and economic activities increasingly provokes conflicts of interest that need to be addressed in natural hazard risk management.

Future needs concerning vulnerability research might include the temporal changes in vulnerability to natural hazards, as well as the spatial characteristics of their magnitude and frequency [27]. During the past decades, European mountain regions as well as Taiwan experienced major transformations in population size, economic conditions, social characteristics and development patterns. As a result of this evolution in socio-economic activity, and an associated relative increase of individual assets, vulnerability might have changed considerably in time and space [28]. Simultaneously, global change processes may alter the magnitude and frequency of hazard processes in mountain regions [29]. To improve natural hazard risk management, these changes should be quantified according to arising institutional, economic, and social implications.

\section{Acknowledgements}

The authors kindly acknowledge the financial support of the following institutions: The Austrian Science Fund (contract L535-N10) for supporting the analyses in the Austrian test sites, the European Union $\left(7^{\text {th }}\right.$ Framework Programme, MOVE project, contract 211590) for insights gained with respect to the situation in the European Alps, and the Soil and Water Conservation Bureau, Nantou, Taiwan, for supporting the field work in Taiwan. Moreover, Margreth Keiler and Sven Fuchs kindly would like to thank the colleagues from the Geotechnical Engineering Research Centre, Sinotech Engineering Consultants, Taipei, Taiwan, for their warm hospitality and the inspiring discussions.

\section{References}

[1] Keiler M. (2012) World-wide trends in natural disasters. In: Bobrowski P. (ed). Encyclopaedia of natural hazards. Springer, Dordrecht, in press.

[2] Hübl J., Fuchs S., Sitter F., Totschnig R. (2011). Towards a frequencymagnitude relationship for torrent events in Austria. In: Genevois R., Hamilton D., Prestininzi A. (eds). Proceedings of the $5^{\text {th }}$ International Conference on Debris-Flow Hazards Mitigation: Mechanics, Prediction and Assessment. Casa Editrice Università La Sapienza, Padova, 895-902.

[3] ONR (2009). Schutzbauwerke der Wildbachverbauung - Begriffe und ihre Definitionen sowie Klassifizierung. ONR 24800. Österreichisches Normungsinstitut, Wien.

[4] Slaymaker O. (1988) The distinctive attributes of debris torrents. Hydrological Sciences Journal 33, 567-573. 
[5] Commission of the European Communities (2007). Directive of the European Parliament and of the Council on the assessment and management of floods. http://eur-lex.europa.eu/LexUriServ/ LexUriServ.do?uri=OJ:L: 2007:288:0027:0034:en:pdf, access 05 February 2012.

[6] Papathoma-Köhle M., Kappes M., Keiler M., Glade T. (2011). Physical vulnerability assessment for alpine hazards: state of the art and future needs. Natural Hazards 58, 645-680.

[7] Fuchs S., Heiss K., Hübl J. (2007). Towards an empirical vulnerability function for use in debris flow risk assessment. Natural Hazards and Earth System Sciences 7, 495-506.

[8] Tsao T.-C., Hsu W.-K., Cheng C.-T., Lo W.-C., Chen C.-Y., Chang Y.-L., Ju J.-P. (2010). A preliminary study of debris flow risk estimation and management in Taiwan. In: Chen S.-C. (ed). Internationales Symposion Interpraevent in the Pacific Rim - Taipei (26-30 April). Internationale Forschungsgesellschaft Interpraevent, Klagenfurt, 930-939.

[9] Totschnig R., Sedlacek W., Fuchs S. (2011). A quantitative vulnerability function for fluvial sediment transport. Natural Hazards 58, 681-703.

[10] Fuchs S. (2009). Susceptibility versus resilience to mountain hazards in Austria - Paradigms of vulnerability revisited. Natural Hazards and Earth System Sciences 9, 337-352.

[11] Cutter S. (2003). The vulnerability of science and the science of vulnerability. Annals of the Association of American Geographers 93, 1-12.

[12] Alexander D. (2005). Vulnerability to landslides. In: Glade T., Anderson M., Crozier M. (eds). Landslide hazard and risk. John Wiley \& Sons, Chichister, 175-198.

[13] Fell R., Corominas J., Bonnard C., Cascini L., Leroi E., Savage W. (2008). Guidelines for landslide susceptibility, hazard and risk zoning for land-use planning. Engineering Geology 102, 85-98.

[14] Central Emergency Operation Center (2009). Typhoon Morakot disaster responses reports from typhoon Morakot Central Emergency Operating Center $74^{\text {th }}$ report. www.nfa.gov.tw/upload/content/2009/20090909/ 2009998323063.pdf, access 05 May 2012.

[15] Lauer W., Frankenberg P. (1988). Klimaklassifikation der Erde. Geographische Rundschau 40, 55-59.

[16] Kappes M., Papathoma-Köhle M., Keiler M. (2012). Assessing physical vulnerability for multi-hazards using an indicator-based methodology. Applied Geography 32, 577-590.

[17] Chen C.-Y., Chen T.-C., Yu F.-C., Hung F.-Y. (2004). A landslide dam breach induced debris flow - a case study on downstream hazard areas delineation. Environmental Geology 47, 91-101.

[18] Brunsden D. (2002). Geomorphological roulette for engineers and planners: some insights into an old game. Quarterly Journal of Engineering Geology Hydrogeology 35, 101-142. 
[19] Melton M. (1958). Correlation structure of morphometric properties of drainage systems and their controlling agents. Journal of Geology 66, 442460.

[20] Johnson P., McCuen R., Hromadka T. (1991). Magnitude and frequency of debris flows. Journal of Hydrology 123, 68-82.

[21] Jakob M., Jordan P. (2001). Design flood estimates in mountain streams the need for a geomorphic approach. Canadian Journal of Civil Engineering $28,425-439$.

[22] Wolman M., Miller J. (1960). Magnitude and frequency of forces in geomorphic processes. Journal of Geology 68, 54-74.

[23] Hjulstöm F. (1935). Studies of the morphological activity of rivers as illustrated by the river Fyris. Bulletin of the Geological Institute 25, 221527.

[24] Crozier M., Glade T. (1999). Frequency and magnitude of landsliding: Fundamental research issues. Zeitschrift für Geomorphologie Suppl. 115, 141-155.

[25] Crozier M. (1999). The frequency and magnitude of geomorphic processes and landform behaviour. Zeitschrift für Geomorphologie Suppl. 115, 35-50.

[26] Holub M., Fuchs S. (2009). Mitigating mountain hazards in Austria Legislation, risk transfer, and awareness building. Natural Hazards and Earth System Sciences 9, 523-537.

[27] Fuchs S., Ornetsmüller C., Totschnig R. (2012): Spatial scan statistics in vulnerability assessment - an application to mountain hazards. Natural Hazards, online first (DOI: 10.1007/s11069-011-0081-5).

[28] Fuchs S., Keiler M. (2012): Space and time: coupling dimensions in natural hazard risk management? In: Müller-Mahn D. (ed). The spatial dimension of risk - how geography shapes the emergence of riskscapes. Earthscan, London, in press.

[29] Keiler M., Knight J., Harrison S. (2010): Climate change and geomorphological hazards in the eastern European Alps. Philosophical Transactions of the Royal Society of London, Series A, 2461-2479. 